\title{
Ecosystem Services and Perception of Water Quality of Lake Barombi Kotto, Cameroon
}

\author{
Awo Miranda Egbe', Beatrice Ambo Fonge1, Pascal Tabi Tabot ${ }^{2}$ \\ 1Department of Botany and Plant Physiology, University of Buea, Cameroon \\ ${ }^{2}$ Department of Agriculture, Higher Technical Teachers' Training College Kumba, Cameroon
}

\begin{abstract}
How to cite this paper: Awo Miranda Egbe | Beatrice Ambo Fonge | Pascal Tabi Tabot "Ecosystem Services and Perception of Water Quality of Lake Barombi Kotto, Cameroon" Published in International Journal of Trend in Scientific Research and Development (ijtsrd), ISSN: 24566470, Volume-3 | Issue-3, April 2019, pp.1739-1746, URL: https://www.ijtsrd. com/papers/ijtsrd2 3529.pdf

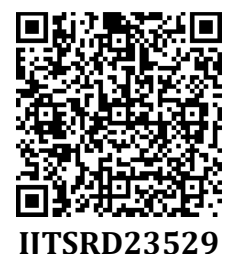

Copyright (c) 2019 by author(s) and International Journal of Trend in Scientific Research and Development Journal. This is an Open Access article distributed under the terms of the Creative Commons

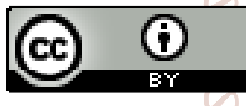
Attribution License (CC BY 4.0) (http://creativecommons.org/licenses/ by $/ 4.0$ )

\subsection{INTRODUCTION}

Lakes carryout a wide range of ecosystem services which can be grouped into four categories: Provisioning, Regulatory, Cultural and Aesthetic services (MEA, 2005; Li and Gao, 2016) and they are mostly valued for these services by the community. Human-dominated ecosystems encompass a wide range of human activities such as agriculture, mining, urbanization and industrialization. These activities disturb the natural ecosystem interactions, creating a complex network of responses with a net effect of accumulation of nutrients, heavy metals, algal and bacterial proliferation there by altering natural processes and functions (Titaet al., 2009; Spanhoffet al., 2012; Fongeet al., 2015). This has led to serious deterioration of most aquatic resources worldwide. A socioeconomic survey in Lake Victoria (Uganda), the second largest freshwater lake in the world revealed that the lake has undergone dramatic changes in its water quality and its fisheries as a result of high anthropogenic pressure (Namisi, 2005). In Cameroon, lakes play a prominent role by serving the needs of agriculture and drinking water but the increasing population coupled with unplanned settlement has led to the pollution of these water sources (Anyinkenget al., 2016). Studies have attributed changes in water quality and associated problems to anthropogenic activities carried out around these water bodies. Societies and communities living around wetlands and aquatic resources are known to impact water resources through different landuse activities e.g residential, agricultural, commercial and industrial wastes/effluents (Wotanyet al., 2013; Fongeet al., 2016). Given the diverse benefits derived from lakes and the surrounding vegetation, so many people have sustained their livelihoods for many years, practicing cultivation within riparian areas (Mathooko, 2001). Understanding and managing these systems, therefore, requires an integrative approach that includes multiple disciplines, such as economics, sociology, and ecology.

Socioeconomic data has been used to establish information regarding changes in the water quality and ecosystem services, investigate the role of wetland communities in maintaining water quality (Tolunet al., 2012). Tsamoet al. (2017) studied the pollution of Lake Mofole in Cameroon by carrying out a socioeconomic survey in the surrounding population prior to the evaluation of the physico-chemical properties of the lake and found that anthropogenic activities around Lake Mofele were responsible for the poor water quality. Corbetet al. (1973) carried out an ecological survey in Lake BarombiKotto and concluded that this lake can be sensitive to anthropogenic pressures. Since then, with the rapid increase in population, very little is known about the socioeconomic dependence of the community on the 
Lake and its riparian vegetation. There is no baseline information regarding the challenges and users perception about the water quality of this lake over the past decades. The overall objective of this study was therefore to collect baseline socio-economic information regarding the benefits of Lake BarombiKotto, the perception of the community about the current water quality and associated water quality challenges. The specific objectives included the following:

1. To document the benefits of Lake BarombiKotto and its riparian vegetation to the BarombiKotto community.

2. To assess respondents' awareness on Lake BarombiKotto water quality and

3. To assess challenges associated with lake and forest resource use.

\subsection{Materials and methods}

\subsubsection{Description of Study Area}

BarombiKottoa village in Meme Division of the South West Region, Cameroon. It contains the famous volcanic crater lake called Lake BarombiKotto. It is found at $4^{\circ} 28^{\prime} \mathrm{N}$ and 9¹6 'E (Awoet al., 2018). It surrounds two islands, the main Island which is inhabited by the natives of BarombiKotto and the Sacred Island, occupied by a dense vegetation which harbours wild birds and animals. Out of this lake is another settlement where non-natives live. The main occupation is cocoa farming and fishing. The total population of this community is estimated at 4000 inhabitants (Ndamukonget $a l ., 2001)$. The main water input into this lake is from an inflowing stream called Tung Nsuria, from which potable water is fetched. This lake forms a confluence with River Meme through an out-flowing stream called Nkondung. This region is characterized by two climatic seasons, the rainy season (March-October) and a dry season (NovemberFebruary).

\subsubsection{Pilot testing and administering of questionnaires a} Prior to data collection, a reconnaissance survey was carried out in the study area to observe the current state of the lake and its riparian forest. This was followed by consultative meetings with the elders of the BarombiKotto Traditional Council. From this meeting, a list of those who had lived in the community above 5 years and are actively using Lake BarombiKotto and its forest resources was generated. This constituted the target population. The questionnaire was pilot tested on 50 individuals who were part of the target population but not part of the sampled population as described by Ezeh (2017). A sample of the questionnaires and Informed Consent Form are included in Appendices 1 and 2 respectively.

Data gotten from the trial test was used to establish the reliability of the instruments. The reliability of was measured using the estimate of internal consistency (Cronbach's Alpha method). The questionnaire was seen to be very reliable with a general reliability coefficient of 0.837 . The reliability was also tested based on the 3 groups of items that represented the 3 constructs under test and they all appeared to be very reliable (Appendix 3). Two hundred semi-structured questionnaires were purposively administered to inhabitants of the BarombiKotto village during two months of field study (June and July 2016). The purposive sampling technique was used to target those who had lived for atleast five years in that community since they likely had vital knowledge especially historical knowledge about the lake.In detail, the respondents were asked if certain issues related to the environment had changed over time and were given the option to disagree or agree. In the case of agreement the respondent was asked to describe the nature of the change.To identify the relative importance between the perceived changes, the respondents were asked to rate its magnitude.

\subsubsection{Statistical analyses}

In general, quantitative data were obtained applying a Likert-type rating scale with the following levels: $1=$ Disagree, $2=$ Strongly Disagree, $3=$ Agree, 4= Strongly Agree, and $0=$ Neutral (Likert 1932). The answer "do not know" was not rated. The scoring process was facilitated by using cards illustrating each level of the scale, a simplified version of the Q-sort method (Kerlinger 1964).

Mean scores were calculated for each item and grand means were calculated for each construct. The mean score of 2.5 was considered as the cutoff score. Mean scores of 2.5 were considered to be neutral, mean scores $\leq 1.25$ were considered to be strongly disagree, mean scores $>1.25$ and $<$ 2.5 were considered to be disagree, mean scores $>2.5$ and $<$ 3.75 were considered to be approved while means $\geq 3.75$ were considered to be highly approved. The level of association between variables was determined using Chisquare association tests. All statistical analyses were performed using SPSS version 17.

\subsection{Results}

\subsubsection{Demographic information}

The demographic information of respondents in the BarombiKotto community is presented in Table 1. Views of 100 males and 100 females were captured in this study. Three age groups were classified in this study: Youth (18-30 years), Adult (31-59 years) and Old ( $>59$ years). Fourty percent of the respondents were old while $30 \%$ of respondents were youths and the other $30 \%$ were adults. The educational level of respondents was predominantly primary school level while the 8-10 family size was the most common. The primary occupation of respondents was farming while other income generating activities included carpentry/bricklaying, teaching, bike riding, Fishing and trading.

\subsubsection{Use of Ecosystem services among respondents in BarombiKotto Community}

Results of the use of ecosystem services across gender and age groups of respondents is presented in Table 2. The uses of Lake BarombiKotto range from the provision of fish and other aquatic animals, provision of water for drinking and domestic purposes, means of transportation, recreation and used for cultural purposes. Some of the observed benefits derived from the lake and its riparian forest are shown in Plate 1.

\subsubsection{Educational level and use of Lake Ecosystem services}

There was no significant association between age range, educational level of respondents and provisional ecosystem benefits like the provision of fish, water for domestic purposes and irrigation $\left(X^{2}=58.22, \mathrm{df}=3, \mathrm{P}=0.54\right)$. There was a significant difference in the awareness of respondents about the indirect ecosystem services (intangible services) like hydrological regulation and local climate regulation $\left(\mathrm{X}^{2}\right.$ $=22.22, \mathrm{df}=3, \mathrm{P}=0.00$ ). There was a $90 \%$ awareness among respondents, with all respondents with tertiary and 
secondary level of education (100\%) being aware of some intangible ecosystem services. Eighty percent (80\%) of respondents in the primary level of education were aware while $100 \%$ of those with no formal education exhibited awareness about these other ecosystem services (Table 3).

\subsubsection{Waste management and sanitation practices of respondents in BarombiKotto community}

Information on the general sanitation, waste disposal and management in BarombiKotto community is presented in Table 4 . There was a $100 \%$ acceptance by respondents of the absence of a conventional waste management facility in the community. The various waste disposal methods ranged from open dumps behind the houses of respondents to burning. None of the respondents disposed of waste directly in Lake BarombiKotto. As concerns the possession of toilets by respondents, a great proportion of respondents strongly agreed to defaecate in pit toilets while $5 \%$ neither owned a pit toilet nor a modern water cistern. Only $1 \%$ of respondents made use of modern water cisterns or flushing toilets.

\subsubsection{Perception of respondents towards Lake BarombiKotto water quality}

The responses to the attributes of water quality of Lake BarombiKotto by respondents are presented in Table 5 . There were variations in the perception of water quality among age groups and educational levels of respondents. There were significant differences in the mean responses by respondents to the various water quality attributes like Lake colour/transparency, lake depth, taste of water. As concerns water colour/transparency, $65 \%$ of respondents (130 respondents) agreed that water transparency has greatly reduced over time while 30\% (60 respondents) did not agree. $5 \%$ of respondents (10 respondents) remained neutral. For the lake depth, $75 \%$ of respondents $(150$ respondents) agreed that the lake depth has decreased while $15 \%$ of respondents (30 respondents) disagreed. $10 \%$ respondents were neutral.

There was a very strong agreement to the respondents perception about fish stock. A large proportion (90\%) of respondents strongly agreed that the fish stock of Lake BarombiKotto has declined and all of them (100\%) agreed that some fish species have gone extinct from the lake. A total of $75 \%$ of respondents (150 respondents) attributed the changes in fish stock to high fishing rate while $20 \%$ disagreed. A small proportion (5\%) were neutral. All respondents (100\%) strongly agreed that typhoid, bilharzia and gastrointestinal disorders like dysentery and diarrhoea were common in their households. With regards to the overall perception of causes of the water quality changes, $75 \%$ of respondents attributed the changes to anthropogenic activities around the lake while $20 \%$ attributed it to natural phenomena. A small proportion (10\%) (20 respondents) were neutral.

\subsubsection{Attitude towards lake use by respondents}

Although a large proportion of respondents was aware of the changes in water quality, the attitude of respondents towards the use of this lake did not change. Only $14 \%$ of respondents sterilized water before use. As as concerns attitude towards swimming and other recreational activities, $94.5 \%$ respondents (189 respondents) still accepted to carryout swimming and other contact recreational activities in Lake Barombi despite their awareness about the changes in water quality (Table 6).

\subsubsection{Educational level of respondents and their perception of Lake BarombiKotto water quality changes}

Education was found to influence respondents' perception of water quality changes. There was a significant association between perception of water quality and level of education $\left(X^{2}=85.714, d f=3, P=0.00\right)$. Sixty percent of respondents in primary level (60 respondents) were not aware about Lake BarombiKotto water quality changes while 40\% (40 respondents) were aware of the water quality changes. For those with secondary education, $100 \%$ (20 repondents) were aware about the changes while $100 \%$ of those with no formal education were also aware of the water quality changes. In total, there was $70 \%$ awareness among respondents of water quality changes in Lake BarombiKotto (Table 6).

\subsubsection{Age and water quality perception}

There was a significant association between the awareness and age of respondents $\left(X^{2}=73.01, d f=2, P=0.00\right)$. The old ( $>59$ years) were more aware of the changes in water quality than the youths and adults. $100 \%$ of the old $(80$ respondents) were aware of these changes while $66.7 \%$ of adults (40 respondents) were aware. Only $33.3 \%$ of the youths displayed a level of awareness (Table 7).

\subsubsection{Ecosystem services of riparian forest of Lake BarombiKotto}

Results of the use of ecosystem services across gender and age groups of respondents is presented in Table 8 . Ecosystem services ranged from provisioning services (wood for fuel and construction, medicinal plants, animals for hunting to aesthetics), aesthetic/cultural to supporting ecosystem services including watershed protection, lake purification and microclimate regulation.

\subsubsection{Awareness on current practices around riparian} forest and sustainability

Attributes used to assess the level of awareness of respondents and their perception about riparian forest management are presented in Table 9. A majority of respondents (150 respondents, $75 \%$ ) agreed that the forest closest to the lake should be protected from community use while $10 \%$ (20 respondents) disagreed, 15\% respondents (30 respondents) were neutral. Most of the respondents (75\%) strongly agreed that the riparian forest was a private property while $15 \%$ disagreed. There was a $100 \%$ agreement that most of the riparian forest has been converted to agricultural farmlands. As concerns land ownership around Lake BarombiKotto, 10\% (20 respondents) agreed to own a land around this lake and all of those who owned land agreed to be using agrochemicals on it $(100 \%)$. Based on subject of sustainability of the riparian forest, $50 \%$ of respondents (100 respondents) strongly agreed that the forest will continue providing ecosystem services for the future generations while 15\% (30 respondents) disagreed and $20 \%$ (40 respondents) remained neutral.

Based on these responses, the level of awareness towards sustainable management was tested. Results revealed that, level of education had a strong association with awareness of sustainable management practices $\left(X^{2}=151.184, \mathrm{df}=6, \mathrm{P}=\right.$ 
0.00). The highest proportion of awareness was found to be demonstrated by respondents with secondary and tertiary education (100\%) while the lowest level of awareness was found in those with primary education. This gave an overall awareness of $40 \%$ among respondents. (Table 10 ).

\subsubsection{Observed drivers of change during the survey}

Based on the observations during the survey, there were several evidences which could be driving the changes in water quality of Lake BarombiKotto and forest structure of its riparian vegetation (Plate 2). Given that the lake surrounds the main Island settlement, most of their open dumping sites where domestic waste is thrown were located very close to the lake shores (Plate 2A). Most portions of this lake were experiencing eutrophication (Plate 2D). There were also dense stands of submerged aquatic plants (Plate $2 \mathrm{E})$. Also, large trees in the riparian forest were selectively logged for different uses, creating large gaps in the forest (Plate 2B and Plate 2F). Most portions of riparian soils with reduced vegetation where experiencing soil erosion (Plate 2C).

\subsection{Discussion}

\subsubsection{Use of Ecosystem services among respondents in} BarombiKotto Community

The socioeconomic survey revealed that the provision of water for drinking, domestic purposes, irrigation, recreational purposes like swimming and cultural activities are the various benefits derived from Lake BarombiKotto. Youths, adults, the old including all their household members carry out various activities in this Lake. This is in line with findings of Mathooko (2001) who found that washing of dresses, swimming, bathing and water abstraction are key anthropogenic activities in the humid zones of Njoro River, Kenya. The use of Lake BarombiKotto by respondents did not vary across gender, educational level and age groups. This can be due to the fact that, this lake is the prime source of potable water in the BarombiKotto community. This makes the community to rely solely on it for their source of both water for drinking and other domestic purposes. Lake Mboandong, which is another lake located in BarombiKotto is considered to be very dangerous and not suitable for recreational activities. Another reason is the central location of Lake BarombiKotto which makes it very accessible compared to Lake Mboandong which is located in the forest. Hence this makes Lake BarombiKotto to be fully exploited by the community.

Respondents were also aware of intangible or indirect services rendered by this lake e.g. hydrological regulation and the regulation of local climate. This was reflected in their levels of education. Those with secondary, tertiary education and even those with no formal education also demonstrated a high level of awareness about the intangible ecosystem services. The awareness of those with no formal education could be due to the fact that, this class was dominated by old people who exhibited a high indigenous knowledge about Lake BarombiKotto. A similar trend was observed for forest ecosystem services. Respondents also depended on the riparian forest for services like the provision of fuel wood, wood for the construction of houses, animals for poaching and as a source of medicinal plants. BarombiKotto being a cocoa-producing community depends so much on wood from the forest for the drying of cocoa which is the main cash crop in this area.
Evidence from the reconnaissance and data from the survey identified agriculture around the lake, harvest of wood for construction, high fishing rates, increasing abundance of aquatic weeds as major threats to Lake BarombiKotto and its riparian vegetation. Another threat to this forest was the effect of grazing by animals as evidenced by the presence of faeces of animals like cows and goats during the survey. These threats have been classified as drivers of ecosystem change (MEA, 2005). Most of the respondents in the study had large household sizes of 8-10 members and above. This indicates a very high pressure on both forest and lake for the sustenance of their livelihood.

\subsubsection{Waste management and sanitation of} respondents in BarombiKotto community

Findings from the socioeconomic survey revealed the absence of conventional waste management facilities in BarombiKotto community with a majority of respondents disposing domestic waste in open dumps behind the house. This, coupled with the absence of good well-constructed toilet facilities increases the risks of faecal contamination of Lake BarombiKotto especially during rainfall events as most of this waste is found at the shores of the lake.

\subsubsection{Perception and attitude of respondents towards Lake BarombiKotto water quality changes}

All respondents with secondary and tertiary education strongly agreed to the fact that the lake water quality has changed. It was found that water quality attributes like transparency, lake depth, and other parameters aquatic weeds and fish stocks have changed in Lake BarombiKotto. Studies have correlated poor water quality to changes in these parameters. Tabotet al. (2016) correlated low transparency and presence of aquatic weeds in Lake BarombiMbo to poor water quality. Old and adults were able to perceive the water quality changes and the associated parameters as a result of their long stay in the community than youths. With respect to the decline in fish stock, respondents attributed it partly to the high fishing rates by fishermen and partly as a result of the changes in water quality. The high poverty and lack of other alternatives could explain why the population depended so much on the fish thereby depleting the fish population. The high fishing rate does not allow fish species to grow to maturity before being harvest and this affects the reproductive population and other fish population dynamics.

The causes of water quality changes according to respondents were partly as a result of anthropogenic activities around the settlement and surrounding agricultural farms. This is in line with studies of Tolunet al. (2012) who found that agricultural expansion is responsible for $50 \%$ decline in water quality and ecosystem services in Izmit bay, Turkey. Spänhoffet al. (2012) also documented the effects of land use activities on water quality in Saxony, with a reduction in transparency, stream depth, changes in colour and chemical properties correlated to landuse activities around the streams. Another cause of water quality changes according to respondents was natural factors like climate change. Studies have documented the effects of climatic variability and climate change on water quality and associated plant and animal lifeforms. Studies by Whitehead et al. (2009) found that the increased frequency and intensity of rainfall associated with climate change causes the remobilization of substances in surrounding land into the aquatic environment and this is responsible for the 
alterations in water transparency and the in-filling of most lake bottoms. Fish and other aquatic species not well adapted to these changes may face local extinctions.

There was a high level of awareness among respondents about the decline in fish stock in Lake BarombiKotto. Corbetet al. (1973) examined the different types of fishes in Lake BarombiKotto and listed about eight different species of tilapia present including their feeding habits. These included (Sarotherodongalilaues (Kurukuma), Tilapia kottae (finkunle), Tilapia miriae(Finjongo), Hemichromisfaciatus (Fibus), Chromidotilapiaguntheriloennbergi (ntandt), Barbuscallipterus (ngete). According to key informants in this study, some of these species have experienced local extinctions especially Barbuscallipterus locally called ngetein Barombi language while there has been remarkable decrease in fish stock compared to previous decades. In response to this decline, the traditional authorities have implemented a periodic fish ban which prohibits fishing in the lake during a specified period of the year. Despite the increase in fish stock as a result of the ban, there is still increased murkiness of the water in Lake BarombiKotto suggesting the likelihood of an environmental problem.

\subsubsection{Challenges associated with resource use}

There was a high incidence of diseases like typhoid, gastrointestinal disorders like dysentery, diarrhoea and urinary infections like bilharzia among respondents and their household members. This is confirmed by recent studies by Campbell et al. (2017) on urogenital schistosomiasis and soil transmitted helminthiasis in Cameroon who recorded high prevalence of this disease in the BarombiKotto community. Lake BarombiKotto is one of the foci of schistosomiasis in Cameroon. Lake BarombiKotto has an endemic species, Bulinuscamerunensis which is the main vector of bilharzia. Bilharzia (Schistosomiasis) is expected to be high amongst the population because of the routine recreational activities like swimming which exposes them to the vector. Similar findings were made by Tsamoet al. (2017) in Lake Mofole, Cameroon where respondents suffered from biharzia as a result of the pollution of the Lake. The high prevalence of enteric diseases among respondents also suggests a possible faecal contamination. The indiscriminate waste disposal and poorly constructed pit toilets in both the Island settlement and the non-native settlement makes this lake to be vulnerable to fecal contamination. The topography of BarombiKotto especially that of the Island settlement makes it easy for waste from dumping sites to be washed off during rainfall drain into the lake.

\section{Acknowledgements}

We remain indebted to the entire BarombiKotto community for their support and availability during the field survey and administering of the questionnaires. Special thanks go to MrBakohNdinkoka for coordinating the questionnaire administering process.

\section{REFERENCES}

[1] Anyinkeng N., Mih, A. M., Tening, A. S., Awah, C. C., 2016. Phytoplanktion diversity and abundance in water bodies as affected by anthropogenic activities within Buea municipality, Cameroon. Journal of Ecology and Natural Environment8 (7): 99-114.
[2] Campbell, S. J., Stothard, J. R., O' Halloran, F., Sankey, D., Durant, T., Ombede, D. E., Chuinteu, G. D., Webster, B .L., Cunningham, L., LaCourse, E. J., Tchuenté, L. T. 2017. Urogenital Schistosomiasis and Soil-transmitted Helminthiasis (STH) in Cameroon: An epidemiological update at BarombiMbo and BarombiKotto crater lakes assessing prospects for intensified control interventions. Infectious Diseases of Poverty 6:49-63.

[3] Corbet, S. A., Green, J., Griffith, J. Betney, E. 1973. Ecological studies on crater lakes in West Cameroon, Lakes Kotto and Mboandong. Journal of Zoology170: 309-324.

[4] Ezeh, C. V. (2017). Influence of Adolescent peer status on critical thinking test. Journal of Psychology and Social Studies1 (1): 11-23.

[5] Fonge, B. A., Tabot, P. T., Chop, A. M., Mumbang, C., 2015. Phytoplankton community structure and physico-chemical characteristics of streams flowing through an agro- plantation complex in Tiko, Cameroon. Journal of Ecology and Natural Environment7 (5): 170-179.

[6] Li T., and Gao, X. (2016). Ecosystem Services Valuation of Lakeside Wetland Park beside Chaohu Lake in China. Water 8: 301-320.

[7] Mathooko, J. M. (2001). Disturbance of a Kenya rift valley stream by the daily activities of local people and their livestock. Hydrobiologia458: 131-139.

[8] MEA 2005. Millennium Ecosystem Assessment. Chapter 20 Inland Water Systems. In: Hassan R, Scholes R, Ash N eds Ecosystems and human wellbeing: current state and trends, Volume 1. Washington, Island Press.

[9] Minitab 17 Statistical Software (2010). [Computer software]. State College, PA: Minitab, Inc. (www.minitab.com)

[10] Namisi, P. (2005). Social and economic implications of Fishery distribution patterns on Lake Victoria, Uganda. LVEMP Socio-economic Research Report 3. NAROFIRRI, Jinja.

[11] Spänhoff, B., Dimmer, R., Friese, H., Harnapp, S., Herbst, F., Jenemann, K., Mickel, A., Rohde, S., Schönherr, M., Ziegler, K., Kuhn, K. and Müller, U. 2012. Ecological Status of Rivers and Streams in Saxony (Germany) according to the Water Framework Directive and Prospects of Improvement. Water4: 887-904.

[12] Tabot, P. T., Che, C. A. and Fonge, B. A. 2016. Water quality of Lake BarombiMbo, a Volcanic Crater Lake and associated point sources. International Journal of Current Microbiology Applied Science5 (7): 518-536.

[13] Tita, M. A, Kamgang, K. B, Tsala, G. N. 2009. Microbial pollution of surface water and its health impact in the Nkoup River Basin in Foumbot, West Cameroon. Journal of Microbiological Research 8:52-57.

[14] Tolun L. G., Ergenekon, S., Hocaoglu, S. M., Donertas, A. S., Cokacar, T., Husrevoglu,S., Beken, C. P. and Baban, A. 2012.Socioeconomic Response to Water Quality: a First Experience in Science and Policy Integration for the Izmit Bay Coastal System. Ecology and Society 17(3): 40.http://www.ecologyandsociety.org/vol17/iss3/art 40/. 
[15] Tsamo, C., Paltahe, A. and Deli, T. 2017. Investigating the Pollution of Lake Mofole (Cameroon) Using Field Studies, It's Water, Sediments, Fish Content and Nearby Well Water. American-Eurasian Journal of Agriculture and Environmental Science 17 (1): 22-29.

[16] Whitehead, P. G., Wilby, R. L., Battarbee, R. W., Kernan, M. and Wade, A. J. 2009. A review of the potential impacts of climate change on surface water quality. Hydrological Sciences Journal54:101-123.
[17] Wotany, E. R., Ayonghe, S. N., Fantong, W. Y., Wirmvem, M. J. and Ohba, T. 2013. Hydrogeochemical and anthropogenic influence on the quality of water sources in the Rio del Rey Basin, South Western, Cameroon, Gulf of Guinea. African Journal of Environmental Science and Technology7 (12): 10541070

Table 1: Age, Educational level, Family sizes and occupation of respondents in BarombiKotto community

\begin{tabular}{|c|c|c|c|c|c|c|c|}
\hline \multicolumn{2}{|c|}{} & \multicolumn{3}{c|}{$(\%)$ Male } & \multicolumn{3}{c|}{$(\%)$ Female } \\
\hline \multirow{4}{*}{ Educational } & No formal & 0 & 5 & 10 & 0 & 5 & 10 \\
level & Primary & 10 & 5 & 10 & 10 & 5 & 10 \\
& Secondary & 2.5 & 2.5 & 0 & 2.5 & 2.5 & 0 \\
& University & 2.5 & 2.5 & 0 & 2.5 & 2.5 & 0 \\
\hline \multirow{5}{*}{ Family sizes } & $0-3$ & 2.5 & 2.5 & 0 & 2.5 & 0 & 2.5 \\
& $4-7$ & 5 & 5 & 5 & 5 & 2.5 & 2.5 \\
& $8-10$ & 7.5 & 7.5 & 15 & 7.5 & 7.5 & 15 \\
& $>10$ & 0 & 2.5 & 0 & 0 & 2.5 & 0 \\
\hline \multirow{5}{*}{ Marital status } & Unmarried & 5 & 5 & 0 & 5 & 5 & 2.5 \\
& Married & 10 & 10 & 17.5 & 10 & 10 & 17.5 \\
& Divorced & 0 & 0 & 2.5 & 0 & 0 & 0 \\
\hline \multirow{5}{*}{ Occupation } & Farming & 15 & 15 & 20 & 15 & 15 & 20 \\
& Carpentry & 2.5 & 0 & 0 & 0 & 0 & 0 \\
& Teaching & 2 & 1 & 1 & 1 & 0 & 0 \\
& Bike riding & 5 & 0 & 0 & 0 & 0 & 0 \\
& Trading & 2.5 & 3 & 0 & 4 & 1 & 0 \\
\hline
\end{tabular}

$\mathrm{Y}=$ Youth, $\mathrm{A}=$ Adult, $\mathrm{O}=$ Old

Table 2: Lake Ecosystem goods and services use among gender and age group of respondents in BarombiKotto community

\begin{tabular}{|l|c|c|c|c|c|c|}
\hline \multicolumn{1}{|c|}{ Response (uses) } & \multicolumn{5}{|c|}{ Gender (\%) } \\
\hline \multicolumn{1}{|c|}{} & M & A & O & Y & A & O \\
\hline Consume fish from the lake & 15 & 15 & 20 & 15 & 15 & 20 \\
\hline Water for domestic uses & 15 & 15 & 20 & 15 & 15 & 20 \\
\hline Water for irrigation & 15 & 15 & 20 & 15 & 15 & 20 \\
\hline Water for swimming & 15 & 15 & 20 & 15 & 15 & 20 \\
\hline Water for transportation & 15 & 15 & 20 & 15 & 15 & 20 \\
\hline Cultural activities & 15 & 15 & 20 & 15 & 15 & 20 \\
\hline Regulates local climate & 5 & 15 & 20 & 15 & 15 & 20 \\
\hline Hydrological regulation & 5 & 15 & 20 & 15 & 15 & 20 \\
\hline
\end{tabular}

$\mathrm{Y}=$ Youth, $\mathrm{A}=$ Adult, $\mathrm{O}=$ Old

Table 3 Educational level and awareness on intangible ecosystem services provided by Lake BarombiKotto

\begin{tabular}{|c|c|c|c|c|c|}
\hline & & & Not aware & Aware & Total \\
\hline \multirow{5}{*}{ Education level } & \multirow{4}{*}{ Primary } & Count & 20 & 80 & 100 \\
& \multirow{4}{*}{ Secondary } & \% within Education level & $20 \%$ & $80 \%$ & $100 \%$ \\
\cline { 2 - 6 } & \multirow{2}{*}{ Tertiary } & Count & 0 & 20 & 20 \\
& & Count & 0 & 20 & 20 \\
\cline { 2 - 6 } & \multirow{2}{*}{ No formal education } & \% within Education level & $0 \%$ & $100 \%$ & $100 \%$ \\
\cline { 2 - 6 } & \multirow{2}{*}{ Total } & Count & 0 & 60 & 60 \\
& & \% within Education level & $0.0 \%$ & $100 \%$ & $100 \%$ \\
\cline { 2 - 6 } & & Count & 20 & 180 & 200 \\
& & & $0 \%$ & $90 \%$ & $100 \%$ \\
\hline
\end{tabular}

Table4: Waste management and sanitation practices of respondents in BarombiKotto community

\begin{tabular}{|l|c|c|c|c|c|}
\hline \multicolumn{1}{|c|}{ Attribute } & SA & A & N & D & SD (\%) \\
\hline The community has a conventional waste management system & 0 & 0 & 0 & 0 & 100 \\
\hline My household uses a water cistern & 1 & 0 & 5 & 90 & 4 \\
\hline My household uses a pit toilet & 90 & 0 & 0 & 0 & 10 \\
\hline
\end{tabular}


International Journal of Trend in Scientific Research and Development (IJTSRD) @ www.ijtsrd.com eISSN: 2456-6470

\begin{tabular}{|l|c|c|c|c|c|}
\hline My household does not have any & 5 & 5 & 0 & 0 & 90 \\
\hline I dispose of waste by burning them & 0 & 5 & 0 & 0 & 95 \\
\hline I throw waste behind open dump behind the house & 95 & 0 & 0 & 0 & 5 \\
\hline I throw waste directly in Lake Barombi Kotto & 0 & 0 & 0 & 0 & 100 \\
\hline SA=strongly Agree, A= Agree, N=Neutral, D=Disagree, SD= Strongly Disagree. & \\
\hline
\end{tabular}

Table 5: Awareness and attitude of respondents towards Lake BarombiKotto water quality

\begin{tabular}{|c|c|c|c|c|c|}
\hline Attribute & SA & A & $\mathbf{N}$ & D & SD \\
\hline Water colour/transparency has changed & 15 & 50 & 5 & 25 & 5 \\
\hline Taste of water has changed & 5 & 5 & 50 & 25 & 15 \\
\hline Lake depth has decreased & 50 & 25 & 10 & 10 & 5 \\
\hline Fish stock has decreased over & 75 & 15 & 5 & 5 & 0 \\
\hline Some fish species have decreased in number or gone extinct & 85 & 15 & 0 & 0 & 0 \\
\hline Aquatic weed have increased in Lake & 50 & 25 & 10 & 10 & 5 \\
\hline Diseases like typhoid, gastrointestinal disorders, bilharzia are common in my household & 100 & 0 & 0 & 0 & 0 \\
\hline Changes in Lake quality are mainly natural & 10 & 10 & 5 & 50 & 25 \\
\hline Changes are caused by man's activities in and around the lake & 50 & 25 & 5 & 10 & 10 \\
\hline Declining fish stock is due to high fishing pressure & 60 & 15 & 5 & 0 & 20 \\
\hline My attititude towards the lake has changed over time & 25 & 5 & 0 & 50 & 20 \\
\hline I now sterilize water before use & 5 & 2 & 0 & 50 & 43 \\
\hline I nolonger swim in the lake & 0 & 5.5 & 0 & 19.5 & 75 \\
\hline
\end{tabular}

$\mathrm{SA}=$ strongly Agree, $\mathrm{A}=$ Agree, $\mathrm{N}=$ Neutral, $\mathrm{D}=$ Disagree, $\mathrm{SD}=$ Strongly Disagree.

Table 6: Educational level and water quality awareness of respondents in BarombiKotto community

\begin{tabular}{|c|c|c|c|c|}
\hline \multirow{2}{*}{ Educational level } & \multirow{2}{*}{ Percent within category } & \multicolumn{2}{|c|}{ CWQ } & \multirow{2}{*}{ Total } \\
\hline & & Not aware & Aware & \\
\hline \multirow{2}{*}{ Primary } & Count & 60 & 40 & 100 \\
\hline & $\%$ within Educational level & & 40 & 100 \\
\hline \multirow{2}{*}{ Secondary } & Count & 0 & 20 & 20 \\
\hline & \% within Educational level & 0 & 100 & 100 \\
\hline \multirow{2}{*}{ Tertiary } & Count & 0 & 20 & 20 \\
\hline & \% within Educational level & 05 & 100 & 100 \\
\hline \multirow{2}{*}{ No formal education } & Count rch and & 0 & 60 & 60 \\
\hline & \% within Educational level & $0 \bigcirc$ & 100 & 100 \\
\hline \multirow{2}{*}{ Total } & Count & 60 & 140 & 200 \\
\hline & $\%$ within Educational level & & 70 & 100 \\
\hline
\end{tabular}

$\mathrm{CWQ}=$ Change in Water Quality

Table 7: Ages of respondents and awareness of Lake BarombiKotto water quality changes

\begin{tabular}{|c|c|c|c|c|c|}
\hline & & & Not aware & Aware & Total \\
\hline \multirow{3}{*}{ Age range } & Youth & $\begin{array}{c}\text { Count } \\
\text { \% within Age range }\end{array}$ & $\begin{array}{c}40 \\
66.7\end{array}$ & $\begin{array}{c}20 \\
33.3\end{array}$ & $\begin{array}{c}60 \\
100\end{array}$ \\
\hline & Adult & $\begin{array}{c}\text { Count } \\
\text { \% within Age range }\end{array}$ & $\begin{array}{c}20 \\
33.3 \\
\end{array}$ & $\begin{array}{c}40 \\
66.7 \\
\end{array}$ & $\begin{array}{c}60 \\
100 \\
\end{array}$ \\
\hline & Old & $\begin{array}{c}\text { Count } \\
\text { \% within Age range }\end{array}$ & $\begin{array}{l}0 \\
0 \\
\end{array}$ & $\begin{array}{c}80 \\
100 \\
\end{array}$ & $\begin{array}{c}80 \\
100 \\
\end{array}$ \\
\hline \multicolumn{2}{|c|}{ Total } & $\begin{array}{c}\text { Count } \\
\text { \% within Age range }\end{array}$ & $\begin{array}{l}60 \\
30\end{array}$ & $\begin{array}{c}140 \\
70\end{array}$ & $\begin{array}{l}200 \\
100\end{array}$ \\
\hline
\end{tabular}

Table 8: Ecosystem services of riparian vegetation around Lake BarombiKotto

\begin{tabular}{|c|c|c|c|c|c|c|}
\hline Responses (Uses) & \multicolumn{5}{|c|}{ Gender (\%) } \\
\hline & \multicolumn{3}{|c|}{ Male } & \multicolumn{3}{c|}{ Female } \\
\hline & Y & $\mathrm{A}$ & 0 & $\mathrm{Y}$ & $\mathrm{A}$ & 0 \\
\hline I harvest wood for construction & 2.5 & 5 & 5 & 0.5 & 0 & 0 \\
\hline I harvest medicine from forest & 2.5 & 7.5 & 10 & 2.5 & 15 & 20 \\
\hline Hunting of animals & 2.5 & 5 & 5 & 5 & 7.5 & 0 \\
\hline Beautifies lake BarombiKotto & 15 & 15 & 20 & 15 & 15 & 20 \\
\hline Cultural activities & 15 & 15 & 20 & 15 & 15 & 20 \\
\hline Forest protects local climate & 5 & 7.5 & 15 & 2.5 & 10 & 10 \\
\hline Purifies Lake Barombi/Watershed & 5 & 10 & 20 & 5 & 7.5 & 15 \\
\hline
\end{tabular}

Table 9: Current practices and attitude towards forest resource use by respondents in BarombiKotto

\begin{tabular}{|c|c|c|c|c|c|}
\hline Attribute & SA & A & $\mathbf{N}$ & D & SD $(\%)$ \\
\hline The peoples' need is more important than protecting the natural environment & 35 & 15 & 15 & 10 & 25 \\
\hline There is no harm if vegetation is cut & 30 & 10 & 0 & 0 & 60 \\
\hline
\end{tabular}


International Journal of Trend in Scientific Research and Development (IJTSRD) @ www.ijtsrd.com eISSN: 2456-6470

\begin{tabular}{|l|c|c|c|c|c|}
\hline The forest closest to lake should be protected from community use & 50 & 25 & 15 & 5 & 5 \\
\hline Forest around lake is private property & 75 & 10 & 0 & 0 & 15 \\
\hline Part of forest has been converted to farmlands & 75 & 25 & 0 & 0 & 0 \\
\hline I own land around the lake & 10 & 5 & 0 & 0 & 0 \\
\hline I use agrochemicals on my land around lake & 10 & 5 & 0 & 0 & 0 \\
\hline Reduced vegetation around lake is due to high logging activities & 100 & 0 & 0 & 0 & 0 \\
\hline $\begin{array}{l}\text { The lake and forest will continue to provide ecosystem services for future } \\
\text { generations }\end{array}$ & 50 & 15 & 20 & 10 & 5 \\
\hline
\end{tabular}

Key: SA=Strongly Agree; A=Agree; N=Neutral; D=Disagree; SD=Strongly Disagree

Table 10: Awareness on sustainability of resource among different educational levels

\begin{tabular}{|c|c|c|c|c|}
\hline Educational level & & Not aware & Aware & Neutral \\
\hline \multirow{2}{*}{ Primary } & Count & 53 & 1 & 46 \\
& \% within Educational level & 53 & 1 & 46 \\
\hline \multirow{2}{*}{ Secondary } & Count & 0 & 20 & 0 \\
& \% within Educational level & 0 & 100 & 0 \\
\hline \multirow{2}{*}{ Tertiary } & Count & 0 & 20 & 0 \\
& \% within Educational level & $0 \%$ & 100 & 0 \\
\hline \multirow{2}{*}{ No formal education } & Count & 21 & 39 & 0 \\
& \% within Educational level & 35 & 65 & 0 \\
\hline \multirow{2}{*}{ Total } & Count & 74 & 80 & 46 \\
& \% within Educational level & 37 & 40 & 23 \\
\hline
\end{tabular}

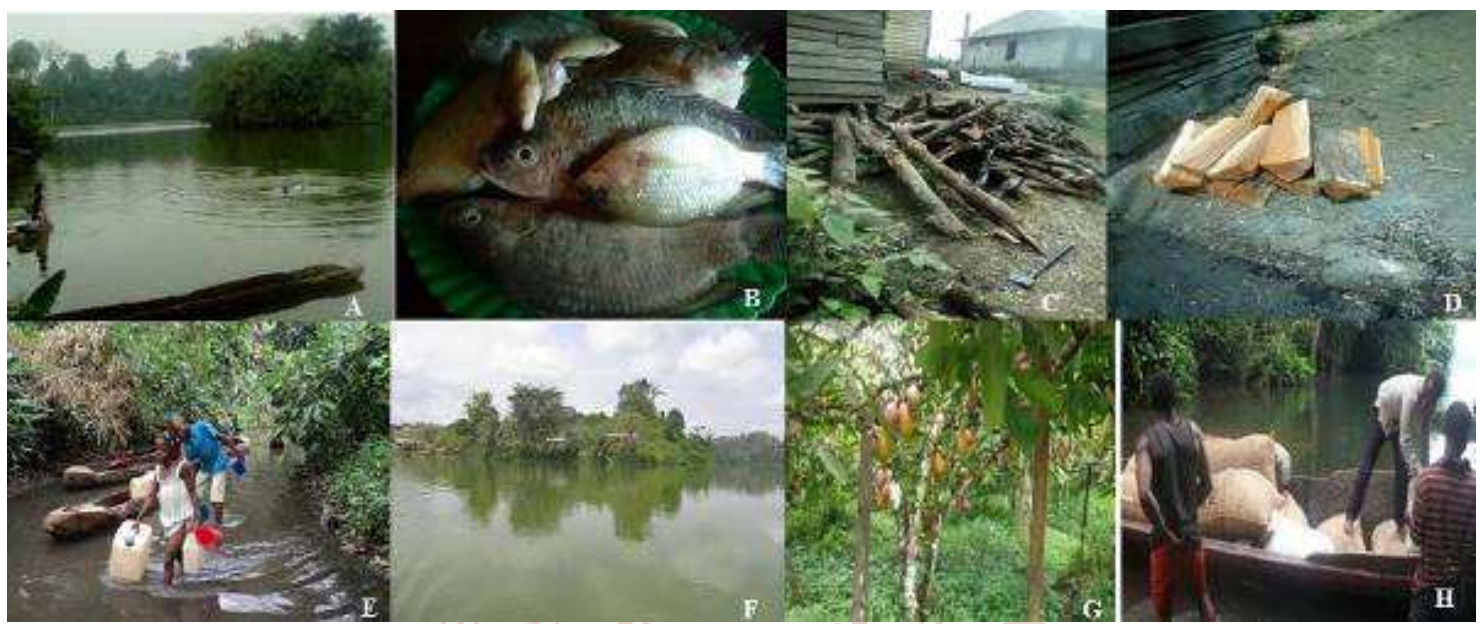

Plate 1: Ecosystem services of Lake BarombiKotto: A- Laundry and swimming in Lake; B-Tilapia fish from Lake; C and D- Fuel wood from surrounding vegetation; $E$ - Children fetching potable water from in-flowing stream; F-Lake BarombiKotto G- Cocoa production; H- Lake as means of transport

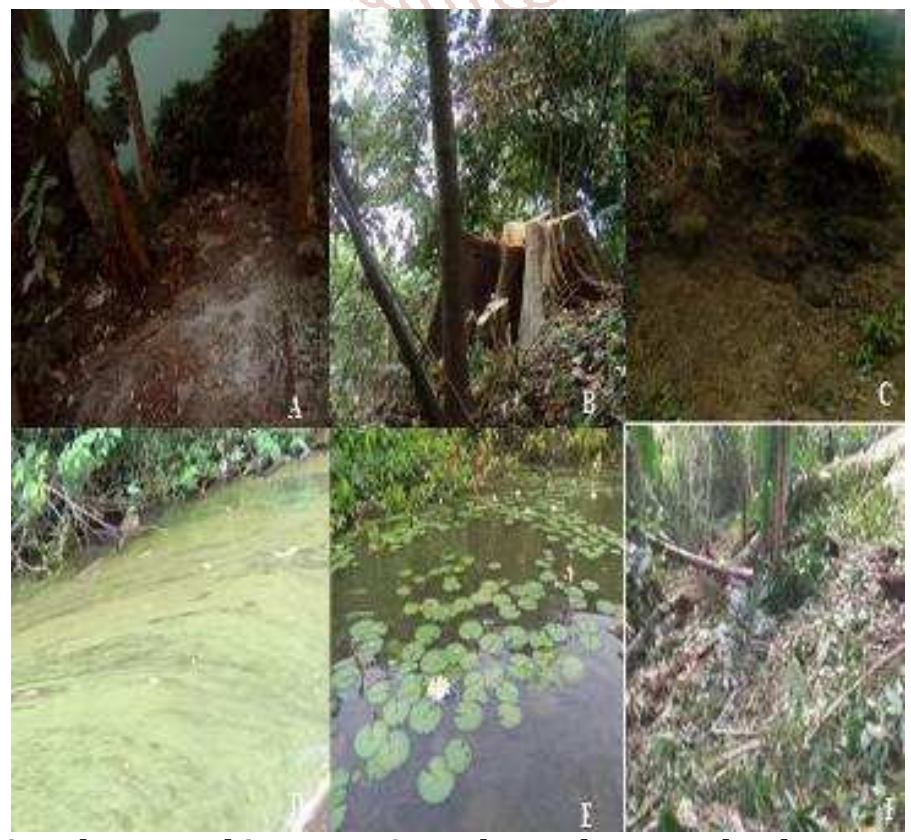

Plate 2: Drivers of change in Lake BarombiKotto A- Open dump close to Lake shore; B- Logging in riparian forest; C- Erosional activity; D- Eutrophication on Lake; E- flating aquatic weeds; F- forest degradation 